\title{
Robot Auxiliary Palletizing Automatic Production Line
}

\author{
Honghua Zhao*, Tao Liu, Zhiping Li, Mianpeng Chen, Qianqian Tian, Yaohua Zhao \\ School of Mechanical Engineering, University of Jinan, Jinan, Shandong Province, China \\ zhhbit@163.com \\ *Honghua Zhao
}

Keywords: Brick; PLC; Grouping; Robot Stacking System

\begin{abstract}
It is of great practical significance to study the new and efficient production methods to overcome the shortage of labor intensity and the low efficiency of the production line under the present situation of artificial palletizing blanks before sintering of brick billet into kiln. This topic is aimed at the development of robot automatic auxiliary production line. Based on single-stage brick slag extrusion, multi-station sensor detection with PLC as the control core achieves the exact brick group and fine cloth blank. The use of palletizing billet robot to complete the palletizing blank operation further improves production efficiency to meet the modern production needs and the rapid development of enterprises.
\end{abstract}

\section{Introduction}

Bricks are the indispensable materials for housing construction, and are widely used in urban and rural construction of residential and public buildings such as load-bearing, non-load-bearing walls, roofs and roads ${ }^{[1]}$. With the economic development, land resources become increasingly tense, sustainable development strategy is particularly important. The country recently launched a strong building materials innovation, and has introduced a number of preferential policies to encourage the development of new building materials, limiting the mass production and use of clay brick, in order to achieve energy conservation, land conservation, waste utilization purposes. The state vigorously promotes the development of new wall materials ${ }^{[2]}$, which has made great achievements. Among them, the construction of waste materials, coal gangue and barren hills sand shale as raw material, the use of tunnel kiln roasting production of sintering brick is the building materials industry's most popular new wall materials. China's tunnel kiln annual output has reached hundreds of billions of standard bricks ${ }^{[3]}$.

\section{Production line process}

Robot auxiliary palletizing automatic production line of brick making process mainly including: Quantitative feeding raw materials- Raw materials processing- Extruding and forming- Cutting brick- Robot stacking to kiln car- Drying- Roasting Forming- Unloading brick and packaging.

Robot auxiliary palletizing automatic production line of the specific process: coal gangue, shale and other raw materials with a hammer crusher broken, after the tube sieve refining, and with a multi-bucket excavator, plate feeder transport of clay ratio, And then sent to the mixer to stir. Vacuum hard plastic extruder extruded mud, through the cutting of the blanket, the formation of cloth billet, palletizing billet machine palletizing to the kiln car, and then by the crawler traction 
kiln car to the end of the track. Hydraulic positioning ferry will kiln car ferry to the drying room driving track, drying room hydraulic top car to promote the kiln to the drying room drying. Dry kiln kiln in turn arranged, follow the principle of first-in first-out. Brick drying through the drying room, and then by the ferry ferry to the tunnel kiln track, by the tunnel kiln hydraulic top car to the kiln roof into the tunnel kiln firing. Brick baked into finished brick, the ferry crossing the kiln out of the kiln. Finished brick out of the kiln unloading brick, the empty kiln car by the crawler trailer back to the palletizing position. If the kiln car or crawler is damaged, it can enter the machine repair shop for maintenance.

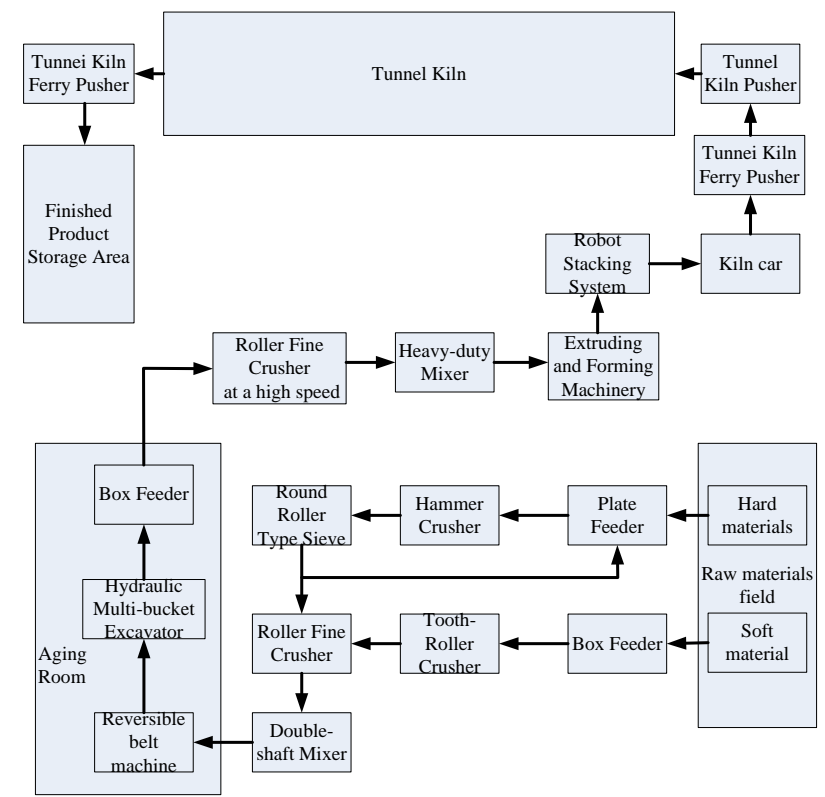

Figure1. Technological process

The overall system composition of the robot auxiliary palletizing automatic production line is shown in Figure 1. Robot auxiliary palletizing automatic production line of the overall system consists of raw material processing system, cutting molding, robot palletizing blank system, kiln transport and other components.

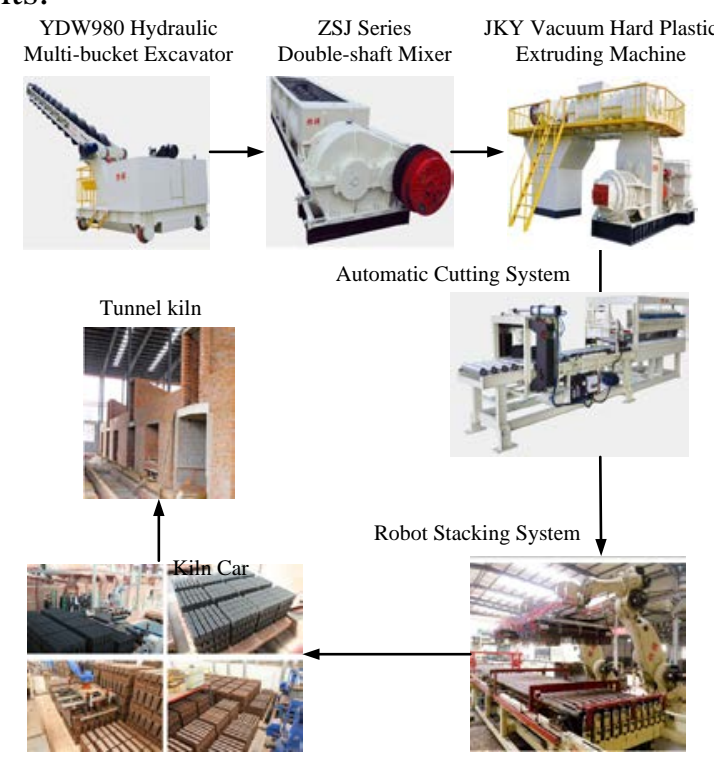

Figure2. The overall system diagram 
As shown in Figure 2, which contains the YDW980 hydraulic multi-bucket excavator, ZSJ horizontal biaxial mixer, JKY vacuum hard plastic extruder, D-type intelligent cutting strip cutting machine, palletizing billet robot, kiln car, crawler, ferry Car, kiln road into the top car machine, in addition to sulfur equipment, tunnel kiln and so on.

\subsection{Cutting Machinery}

At present, the movement principle of the blank automatic cutting machine used in the brick making enterprise is basically the deformation of the crank slider or the cam mechanism ${ }^{[4]}$. The AC motor gearbox external crank slider or cam mechanism is utilized to realize the intermittent cutting. Intelligent cutting machine is a convenient, simple structure, high degree of automatic brick and tile machinery and equipment, mainly by the front-end conveyor system, cut the system and the rapid delivery system ${ }^{[5]}$. Automatic cutting machine first cut into strips of strips, and then quickly transport billet, and then cutting machine cut into pieces of mud.

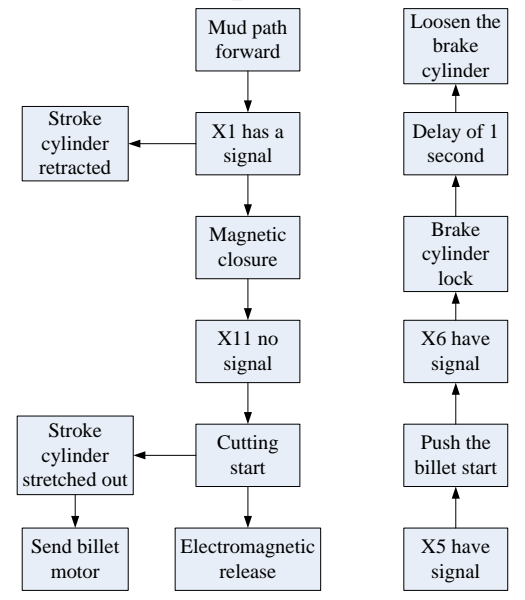

(a) Stripe cutting machine (b)Blank cutting machine

Figure 3. Automatic cutting system as a flow chart

Cutting machinery control core selects Xinjie XC1-24R-C type of PLC. Table 1 is the distribution of input and output ports.

Table 1 Automatic cutting system I/O point distribution

\begin{tabular}{|c|c|c|c|}
\hline \multicolumn{2}{|l|}{ The input } & \multicolumn{2}{|l|}{ The output } \\
\hline Name of the element & $\begin{array}{l}\text { The PLC } \\
\text { address }\end{array}$ & Name of the element & $\begin{array}{c}\text { The PLC } \\
\text { address }\end{array}$ \\
\hline Automatic switch & X0 & The automatic light & $\mathrm{Y0}$ \\
\hline The length of the switch & $\mathrm{X} 1$ & Trip solenoid valve & Y1 \\
\hline After cutting a switch & $\mathrm{X} 2$ & Press the electromagnetic valve & $\mathrm{Y} 2$ \\
\hline Position switch before cutting & X3 & For cutting the cylinder & Y3 \\
\hline Motor points button & $\mathrm{X} 4$ & Send motor running $2.5 \mathrm{~s}$ & Y4 \\
\hline Cutting start switch & $\mathrm{X} 5$ & Send motor running 4s & Y5 \\
\hline Cutting stop switch & $\mathrm{X} 6$ & Send motor running $5 \mathrm{~s}$ & Y6 \\
\hline Automatic billet knob & $\mathrm{X} 7$ & Push the billet motor & Y7 \\
\hline Inching push button & $\mathrm{X} 10$ & The brake solenoid valve & Y10 \\
\hline Electromagnetic power bit & $\mathrm{X} 11$ & The drive motor & Y11 \\
\hline & & Electromagnetic energizing & Y13 \\
\hline
\end{tabular}




\subsection{Robot Stacking System}

The robot system consists of two parts: automatic grouping and robot stacking brick. According to its specific parts of the process can be divided into Billet, Inspection blank, Stockpile, Grouping, Cloth blank, palletizing blank and so on.

\subsubsection{Turn Blank}

The blanking mechanism can be used for different brick types. For perforated bricks and hollow bricks, the direction of the billet hole is likely to cause deformation of the empty brick. In order to avoid the deformation of the empty brick, so the need to add blanking process, to adjust the brick space position. Solid brick does not exist above the gripping brick blank empty deformation of the problem, so no need to turn the blank body. The perforated boring rounds of the robot auxiliary blank production line are shown in Figure 4.
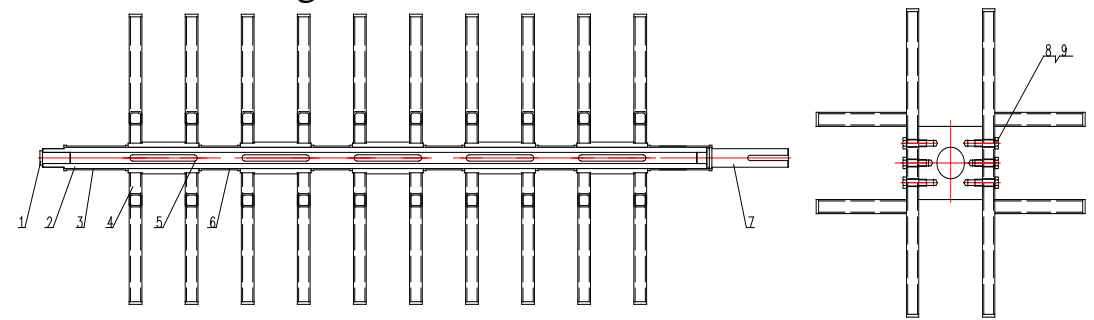

1.on both sides of the wheel 2.long axis 3.long sleeves 4. Flip 5.ordinary flat key 6. short sleeves 7. drive shaft 8 . hex head bolt 9. spring washer

Figure 4 Robot setting porous brick slab turning wheel

The perforated bricks crossed the drive belt and the two perforated bricks were transported from the front side belt to the turn wheel group and rotated by $90^{\circ}$. The hollow brick crimping mechanism is an octagonal star structure. The difficulty is that the blanking mechanism and the front and rear drive belt speed with.

\subsubsection{Automatic grouping}

The accuracy of the brick group and whether the repeat accuracy or not directly affect the success or failure of the blank machine blank. The success of the group is the key to the entire brick production line. The basic function of the group is to combine the multi-station photoelectric sensor to cut the cut brick into the kind of we want to arrange the matrix, so that follow-up palletizing blank ${ }^{[6]}$.

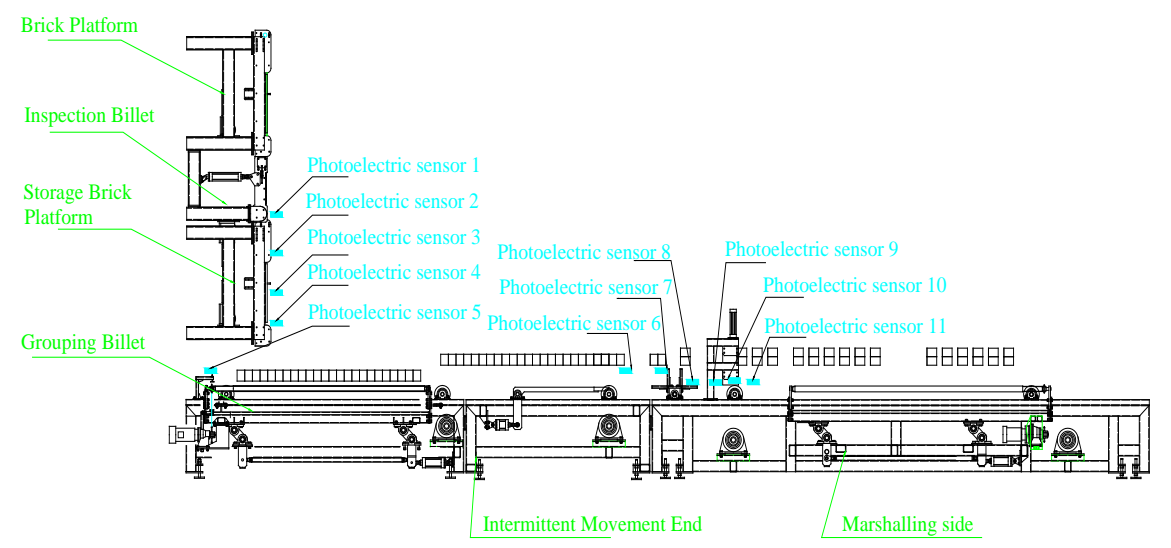

Figure 5. Brick automatic grouping 


\subsubsection{Robot palletizing blank}

Building materials brick production of large-scale production and automation requires advanced brick equipment ${ }^{[7]}$. The robot auxiliary palletizing blank machine is mainly composed of the robot body, the servo drive system, the robot arm mechanism, the end of the actuator (handle), the robot end actuator adjustment mechanism and the detection mechanism. palletizing billet robot model selects NACHI MC470P-01.

The clamping and loosening of the robot chuck is achieved by adding an external power supply and auxiliary relay to the control cabinet, which is controlled by the robot control relay. When the brick reaches the position of the blank, the PLC sends the robot external signal and starts the external regeneration mode.

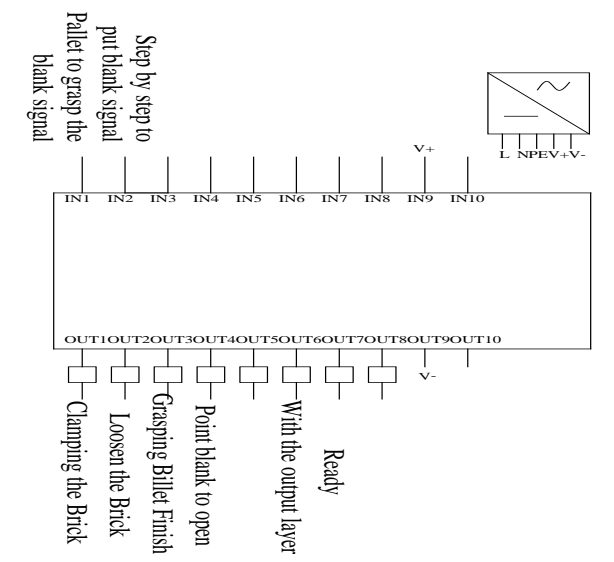

Figure 6. Robot system terminal wiring diagram
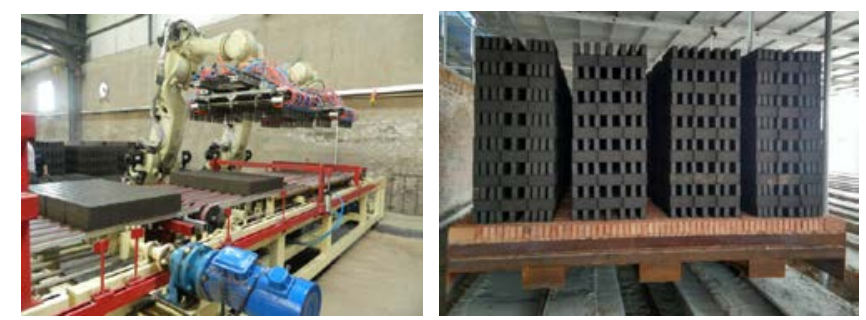

Figure 7. Robot setting and kiln car transport brick physical figure

The requirements of the palletizing billet robot are "flat, stable and straight". Brick palletizing is stable in order to stabilize the non-crooked brick. palletizing into a straight line is for the smooth flow of the channel to improve the quality of brick drying and firing. The size of the hollow brick is $245 \times 115 \times 92(\mathrm{~mm})$. The width of the pneumatic chuck is $68 \mathrm{~mm}$, and the distance between the long direction is $16 \mathrm{~mm}, 18 \mathrm{~mm}$ and $16 \mathrm{~mm}$. The palletizing billet robot can put 48 pieces of standard bricks and 12 layers. A kiln car can put a total of 1152 standard brick.

\subsection{Kiln Operating Machinery}

The kiln transportation system of the kiln project includes kiln car, crawler, hydraulic positioning ferry, hydraulic kiln stepping car and other equipment. Brick was put into the kiln car into the tunnel kiln roasting, first through the drying room drying, and then into the tunnel kiln roasting.

The crawler is used for the brick conveyance equipment in the kiln process and the loading and unloading process.

The hydraulic positioning ferry is the kiln engineering craft production line for the ferry kiln car, which can make the kiln car from the tunnel kiln to another track to another normal circulation. It 
can be manually and remote control dual selection control, easy to operate. Hydraulic positioning ferry is the kiln factory supporting the production equipment.

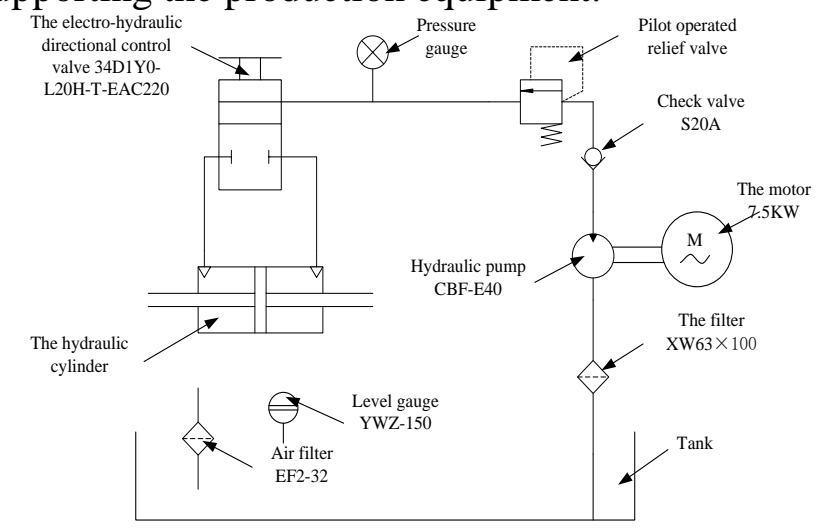

Figure 8. Tunnel kiln ferry pusher hydraulic system schematic diagram

The hydraulic kiln stepping motor function is to push the kiln car on the hydraulic ferry into the tunnel kiln or the drying room and push the kiln car in turn to advance in the tunnel kiln or drying room. It is one of the key equipment for the operation of brick in kiln works.

\section{Conclusions}

Robot auxiliary palletizing production line is a simple production process, rich in function, efficient, efficient, simple operation, economical and practical, a group of precise, flexible operation with independent intellectual property rights of the brick automatic production line. Robot auxiliary palletizing production line to eliminate the original mode of production, and further improve the sintering brick industrial production efficiency and automation unmanned level.

\section{Acknowledgements}

This work was supported by Shandong Province R\&D Key Project Foundation under No.2014GJJS0401, the Project of Shandong Province key research and development program (No. 2016GGX4305), Authors gratefully acknowledge the support.

\section{References}

[1] Ming Xu, Yajuan Wang, Jiyu Zou. The development of the Chinese brick equipment, energy conservation and emissions reduction [J]. Journal of tile world. 2014-09:3-10.

[2] Zhenghong Wu. Our country's present situation and development direction of sintering wall materials and equipment to explore [J]. Journal of brick and tile, 2013 (1) : 33-38.

[3] Fuguang Chen. Brick and tile industry development need to pay attention to several problems [J]. Journal of brick and tile, 2013 (12) : 14 to 20.

[4] Lijun Li. Adobe automatic cutting mechanism optimization design [J]. Mechanical, 1990, 17 (5) : 23-26.

[5] Lijuan Cui. A new type of automatic cutting machine [J]. Journal of brick and tile, 2001, 5:002.

[6] Tao Liu. layer palletizing robot structure design and dynamic analysis [D]. Lanzhou: lanzhou university of technology, 2010.

[7] Ling Gao. The application of robot setting unloading billet system [J]. Journal of building materials submitted to the China. 2012 (3). 